\title{
Ludicidade e aprendizagem significativa na formação de estudantes em educação ambiental: relato de experiência
} Playfulness and meaningful learning in the training of students in environmental education: experience report

\author{
SANTOS, Cláudia Lilian Alves dos. Mestre/Licenciada em Ciências Biológicas \\ Instituto Federal da Bahia- Campus Vitória da Conquista. Av. Sérgio Vieira de Mello, 3150, Zabelê - Vitória da \\ Conquista - Bahia - Brasil. CEP: 45078-000 / Telefone: (77) 3426-3355/ E-mail: claudinha_litian@hotmail.com;
}

CAVALCANTE, Kellison Lima. Mestre/Licenciado em Ciências Biológicas

Instituto Federal de Educação, Ciência e Tecnologia do Sertão Pernambucano - Campus Petrolina. Rua Maria Luiza de Araújo Gomes Cabral, S/N, João de Deus - Petrolina - Pernambuco - Brasil. CEP: 56.316-686 / Telefone: (87) 2101-4300/ E-mail: kellison.cavalcante@ifsertao-pe.edu.br.

\section{RESUMO}

A Educação Ambiental (EA) é uma proposta educativa que visa instruir sobre as práticas sustentáveis, promover debates de ideias diante das questões ambientais e se instaurar uma cultura de utilização racional dos recursos naturais. Diante dessa perspectiva, o presente estudo objetiva relatar a experiência docente da intervenção de Educação ambiental através de práticas lúdicas na formação dos discentes do IFBA. O trabalho foi estruturado em duas etapas: (1) Orientação aos discentes aplicadores da EA e elaboração do plano de ação; (2) Intervenções da EA em duas escolas de Ensino infantil e fundamental I. A intervenção realizada pelos discentes do IFBA em duas instituições de ensino infantil e fundamental I selecionadas foi procedida através de palestras adequadas à faixa etária do público alvo e realização de oficinas de confecção de materiais didáticos e práticas lúdicas. Fomentou-se ações de conservação da biodiversidade por intermédio de intervenção com práticas lúdicas de EA. A veiculação da ludicidade atrelada ao âmbito da EA tem grande relevância no apelo de práticas conservacionistas.

Palavras-chave: Intervenção, Práticas lúdicas, Conservação, Biodiversidade.

\section{ABSTRACT}

The Environmental Education $(\mathrm{EE})$ is an educational proposal that aims to educate about sustainable practices, discuss and debate environmental issues and, establish a culture of rational use of natural resources. From this perspective, the present study reports the teaching experience of Environmental Education through playful practices in the education of IFBA students. The work was structured in two stages: (1) Orientation to students who will do the EE and elaboration of the plan of action; (2) Interventions by the students EE in two primary and secondary schools. The intervention carried out by IFBA students in two selected schools, one of kindergarten and the other, an elementary school, was done through lectures appropriate to the age group of the target audience and workshops for the preparation of didactic materials and playful practices. Actions were taken to conserve biodiversity through intervention involving playful activities. The spread of playfulness in the scope of EE has great relevance in the appeal of conservationist practices.

keywords: Intervention, Playful practices, Conservation, Biodiversity. 
SANTOS, C. L. A.; CAVALCANTE, K. L. (2019)

Ludicidade e aprendizagem significativa na formação de estudantes em educação ambiental: relato de experiência

\section{Introdução}

Educação Ambiental (EA) é uma ferramenta educacional que visa instaurar debates de cunho sócio-ambiental, além de promover a uma conscientização concreta das urgências ambientais. Dentre essas demandas podemos elencar os alertas sobre os impactos dos poluentes no meio ou da aceleração da extinção de espécies de nossos ecossistemas brasileiros desencadeada por ações antrópicas. Nesse aspecto, conforme Camelo (2011) a EA busca implementar uma cultura de utilização racional dos recursos naturais e práticas sustentáveis. Chalita (2004) enfatiza que a educação constitui-se na mais potente de todas as medidas de intervenção e tem por finalidade elaborar novos preceitos e consequente mudança de atitudes. Para Dias (2004), com efeito, as ações da EA devem efetivar práticas conjuntas e cooperativas para a compreensão da natureza em associação com a interdependência dos recursos do meio, a fim de exaurir o consumismo extremo evidenciando o homem como membro integrante do meio ambiente.

Rodrigues; Costa (2004) ressaltam que, de caráter processual e contínuo, a EA implica na provocação de comportamentos, posturas, habilidades e construção de valores do individuo na tomada de medidas para se mitigar as problemáticas ambientais. Esse conhecimento científico, prático e adquirido perpassa de geração a geração, sendo propagado de pai para filho ao longo dos tempos. Para Dias (2004), a EA apresenta um caráter holístico e não homogeneizado do ensino e propõe uma educação com a premissa de se instigar o senso crítico no individuo. Ainda esse mesmo autor enfatiza que ações da EA trazem à tona discussões de cunho ético, social, ambiental e político para uma efetiva transformação de uma realidade.

Embora a EA seja uma abordagem muito propagada hoje em dia, ainda é pouco difundida na prática dentro do espaço escolar sendo restrita a eventos esporádicos e pontuais, e por vezes, não extrapolando os muros das instituições através de práticas de intervenção. Soma-se a existência de uma grande problemática no entorno das práticas atuais voltadas para a conservação da biodiversidade, o uso desenfreado dos recursos naturais e a falta de visibilidade as demandas de apelo ambiental que agrava as ações de preservação da natureza. Todavia, para preservar é necessário antes de tudo conhecer, só se levanta esforços para proteger aquilo que se conhece e a educação ambiental é uma ferramenta de extrema importância para se mitigar essa problemática em questão.

Para Santos (2008), a ludicidade é uma alternativa de ensino importante para o desenvolvimento da saúde mental e necessita de mais espaço no âmbito do processo de ensinoaprendizagem, uma vez que práticas lúdicas proporcionam uma relação de maior afetividade com o mundo, expande a socialização com o outro e com ele mesmo. Nesse entendimento, Tessaro (2009) e Rangel; Miranda (2016), corroboram que as práticas lúdicas educativas possuem a capacidade de prender a atenção do participante, ao passo que, facilita a socialização saberes de forma espontânea e dinâmica, além de estimular a consciência crítica e a criatividade no âmbito pessoal, social e cultural.

Assim, Rangel; Miranda (2016) destacam que atrelados aos programas de educação ambiental, jogos, dinâmicas, e práticas de recreação têm função de maior apelo educacional, pois 
SANTOS, C. L. A.; CAVALCANTE, K. L. (2019)

Ludicidade e aprendizagem significativa na formação de estudantes em educação ambiental: relato de experiência

fogem do ensino tradicional das salas de aula e da rotina escolar. Ainda, os mesmos autores enfatizam a formulação de conceitos inerentes aos participantes e o estímulo no desenvolvimento da autonomia. Dessa forma, Telles (2002) desta que os jogos interativos são apreciados dentro de uma linha pedagógica, o construtivismo, ligada de forma intrínseca a aquisição de conhecimento e a consolidação do aprendizado.

De acordo Cabrera; Salvi (2005), os recursos lúdicos educativos influenciam espontaneamente o indivíduo, pois prepondera pelas fases da vida humana, principalmente quando crianças e persiste de forma mais amena até a fase adulta. Esse viés é potencializado pelo fato destas práticas estimularem os processos motores, cognitivos e afetivos dos participantes. Todavia, Cabrera (2007) enfatiza o lúdico como instrumento institucional efetivo, pois instiga a uma predisposição ao gosto pelo aprendizado no aprendiz, além de proporcionar imaginação para a consolidação de processos cognitivos e a adoção de símbolos para a construção de significados, premissas fundamentais que são próprias da aprendizagem significativa.

De acordo om Pelizzari et al. (2002), a teoria da aprendizagem significativa foi promulgada pelo psicólogo cognitivista David Joseph Ausubel, essa abordagem construtivista prioriza como é processada uma nova informação e como ela se inter-relaciona com os conhecimentos prévios trazidos pela bagagem cognitiva do estudante. Portanto, a partir do entendimento de Nardy; Laburú (2014), a aprendizagem significativa apresenta um caráter especial e sobrepõe aos ensinamentos conceituais, com a pretensão de implementar conteúdos atitudinais e procedimentais que influem na internalização de valores e posicionamentos expressos através de comportamentos.

A veiculação da ludicidade atrelada ao âmbito da EA tem grande relevância no apelo de práticas conservacionistas. Diante desse cenário, a EA utilizada de forma articulada é indispensável na formação e propagação de posturas, atitudes e valores para conservação da nossa biodiversidade. Para Oliveira (2002), a educação ambiental vem minimizar práticas destrutivas que geram impacto direto na conservação da natureza e refletem em considerável impasse ao desenvolvimento sustentável do país. A intervenção e o contato da EA visando à promoção da conservação da biodiversidade sensibiliza a uma empatia a temática trabalhada na prática, ao passo que provoca uma postura de responsabilidade ambiental nos aplicadores da EA.

Segundo os Parâmetros Curriculares Nacionais - PCN's (MEC, 1997), o papel principal dentro da proposta de uma abordagem ambiental é a formação de cidadãos conscientes de forma ativa, capacitados na tomada de decisões perante a desafios na realidade socioambiental e compromissados com o bem-estar em escala local, regional e global. Em adição, para Oliveira (2002), a intervenção de práticas educativas no âmbito ambiental promove maior dinamicidade no que diz respeito a medidas protetivas ao meio ambiente, pois instiga uma relação harmônica entre ser humano e natureza capaz de provocar mudanças comportamentais de cunho ético e socioambiental. Nessa perspectiva, os PCN's (MEC, 1997) ainda apontam a relevância dessas práticas na ação construtiva de uma sociedade ambientalmente sustentável e socialmente justa, a fim de salvaguardar todas as formas de vida existentes e garantir subsídios para a conservação da diversidade e abundancia das espécies do planeta. 
SANTOS, C. L. A.; CAVALCANTE, K. L. (2019)

Ludicidade e aprendizagem significativa na formação de estudantes em educação ambiental: relato de experiência

A construção do conhecimento na EA é conduzida de forma conjunta e articulada, no desafio constante de se arquitetar novas medidas de se praticar o processo de ensino-aprendizagem. Contudo, o estudo em questão vem contribuir na implementação de ações de intervenção a fim de instigar uma percepção voltada para as questões ambientais e sensibilização ao cuidado com os recursos naturais desde as séries iniciais. Diante desse cenário, objetivamos relatar a experiência docente sobre o processo de intervenção de Educação ambiental através de práticas lúdicas e reflexo dessa aprendizagem significativa na formação dos educandos do IFBA, além de subsidiar ações de preservação ambiental na prática.

\section{Material e métodos}

As intervenções das oficinas foram realizadas em duas instituições de ensino infantil e ensino fundamental I situado no extremo da cidade de Vitoria da Conquista-BA, nas proximidades do Instituto Federal da Bahia - IFBA. O projeto de intervenção de educação ambiental foi procedido em duas estapas: (Etapa I) em dezembro de 2018 com a reutilização de material reciclado para conscientização dos recursos naturais e (Etapa II) em fevereiro de 2019 com enfoque em práticas lúdicas voltadas ao reconhecimento dos ecossistemas brasileiros e conservação da biodiversidade. Tendo em vista atender o objetivo proposto, empregamos a abordagem qualitativa para estudo de campo, pois apresentam aspectos que configuram esse tipo de trabalho: (a) fonte de dados extraídos diretamente do ambiente natural; (b) investigação descritiva dos dados qualitativos, conforme Bogdan e Biklen (1994). O delineamento da pesquisa foi embasado no método observacional, através da pesquisa-ação e participante descritas por Thiollent (1985), caracterizada como um tipo de pesquisa social baseada no caráter empírico, tendo o pesquisador envolvido de modo participativo ou colaborativo.

O presente estudo foi estruturado em duas etapas: (1) orientação aos discentes aplicadores da EA e elaboração do plano de ação e (2) intervenções da EA em duas escolas de Ensino Infantil e Fundamental I. O trabalho desenvolvido teve como enfoque dois grupos denominados: (a) "Discentes aplicadores da EA" - alunos do $1^{\circ}$ ano do curso de Meio Ambiente do Instituto Federal da Bahia, Campus Vitória da Conquista (38 alunos) e (b) "Público alvo participativo da EA" - alunos de duas instituições particulares do Ensino Infantil e Fundamental I ( $n=43 ; n=93$ alunos, respectivamente), totalizando 136 indivíduos.

O grupo "Discentes aplicadores da EA" foi subdivido em equipes e redistribuídos de forma aleatória a cada subgrupo do público alvo. Como suporte teórico, os "Discentes aplicadores da EA" obtiveram aulas durante a disciplina de Ecologia Geral, sobre as temáticas de biodiversidade e biomas. A orientação e socialização da proposta de intervenção aos discentes foram articuladas com o auxílio de um esboço de plano de ação para delimitação da oficina por cada uma das equipes.

O plano de ação para planejamento pelos discentes foi roteirizado da seguinte forma: (I) tema; (II) objetivo; (III) instituição de aplicação; (IV) data de aplicação; (V) equipe; (VI) ação a ser adotada (o que?); (VII) atividade delineada (como?); (VIII) responsável em executar cada atividade 
SANTOS, C. L. A.; CAVALCANTE, K. L. (2019)

Ludicidade e aprendizagem significativa na formação de estudantes em educação ambiental: relato de experiência

(quem?); (IX) recursos necessários; (X) recursos solicitados à instituição; (XI) data de início; (XII) prazo de término; (XIII) status e (XIV) observações pertinentes. A intervenção realizada pelos discentes do IFBA nas duas escolas selecionadas foi procedida através de palestras adequadas à faixa etária do público alvo e realização de oficinas de confecção de projéteis e práticas lúdicas.

o relato de experiência buscou esbouçar e discutir seis condicionantes consideradas pertinentes nesse estudo para as práticas de educação ambiental: (a) postura sócio-ambiental; (b) planejamento didático; (c) adoção de estratégias; (d) adequação da linguagem; (e) reutilização de materiais reciclados e (f) uso de tecnologias da informação.

Os condicionantes adotados para a análise dos dados foram previamente procedidos através de uma análise interpretativa dos fatores relevantes durante o processo de intervenção de práticas de EA. Os critérios estipulados para a consolidação desses condicionantes também levaram em consideração elementos significativos no processo de formação estudantil dos discentes aplicadores.

\section{Resultados e discussão}

Os resultados encontrados não são quantificados em valores numéricos, mas em uma análise da condição qualitativa refletida na (re) significação da formação dos educandos e da construção de uma postura de responsabilidade ambiental nos alunos aplicadores das práticas de EA. Para Carvalho (2013), se faz necessário a aproximação em sala de aula dos discentes com o sujeito ecológico, através da participação efetiva e na construção do conhecimento. As práticas mediadas pelos discentes durante o processo de intervenção nas escolas estão dispostas na Tabela 1.

Tabela 1 - Estratégias de práticas adotadas pelos discentes durante o processo de intervenção.

\begin{tabular}{|c|c|c|}
\hline Estratégia de práticas de EA & Especificação/temática & *Etapa \\
\hline Palestras & Uso sustentável dos recursos naturais; Biomas brasileiros & I \\
\hline Pintura facial & Fauna dos biomas brasileiros & II \\
\hline Elaboração de jogos virtuais e interativos & $\begin{array}{l}\text { Que bicho é esse? De quem é essa vocalização? Forca; } \\
\text { Jogo da memória; Quiz }\end{array}$ & II \\
\hline $\begin{array}{l}\text { Produção de máscaras de papel machê e } \\
\text { cartolina }\end{array}$ & Fauna brasileira & II \\
\hline Pinturas em desenhos contextualizados & Ilustrações dos biomas & II \\
\hline Recreação & Brincadeiras diversas & 1 \\
\hline $\begin{array}{l}\text { Confecção de binquedos com material } \\
\text { reciclado }\end{array}$ & Vai-e-vém; Bilboquê; foguete de garrafa pet & I \\
\hline Simulação de ecossistema & Bioma brasileiro & I \\
\hline Confecção de lixeiras & Coleta seletiva & I \\
\hline Teatro musical & S.O.S. Amazônia & II \\
\hline
\end{tabular}

* Nota: A etapa I diz respeito a primeira intervenção de oficinas mediadas pelos estudantes do IFBA e a etapa II faz referência a segunda intervenção de práticas da EA. Fonte: elaborada pelos autores. 
SANTOS, C. L. A.; CAVALCANTE, K. L. (2019)

Ludicidade e aprendizagem significativa na formação de estudantes em educação ambiental: relato de experiência

As práticas executadas extraíram uma nova postura sócio-ambiental nos discentes aplicadores, a aplicabilidade do "aprender a fazer" e o link com as demandas econômico-sociais desse processo instruíram nos discentes uma aprendizagem significativa e contextualizada. Ao se ensinar estratégias de preservação os indivíduos internalizam valores e os reproduzem no seu contexto social. Como ressaltam Campos; Cavalari (2018), tornam-se potenciais educadores ambientais.

Percebe-se o poder de reflexão desse âmbito em uma das palestras ministradas pelos discentes aos estudantes do ensino fundamental I (Figura 1A, B), ao explanar o contexto sócioeconômico no contexto da circulação de resíduos e dos desdobramentos desse dado enfatizam a geração de renda da coleta desses resíduos pelos catadores de latinha e papelão. Moreira (1999) e Carril et al. (2017) definem a aprendizagem significativa quando o indivíduo assimila o conceito e busca associá-lo com sua bagagem de conhecimentos prévios e com sua realidade. De acordo com Diniz (2008), numa visão humana social, a aprendizagem significativa subsidia a inserção da experiência e a vivência do estudante no currículo escolar.

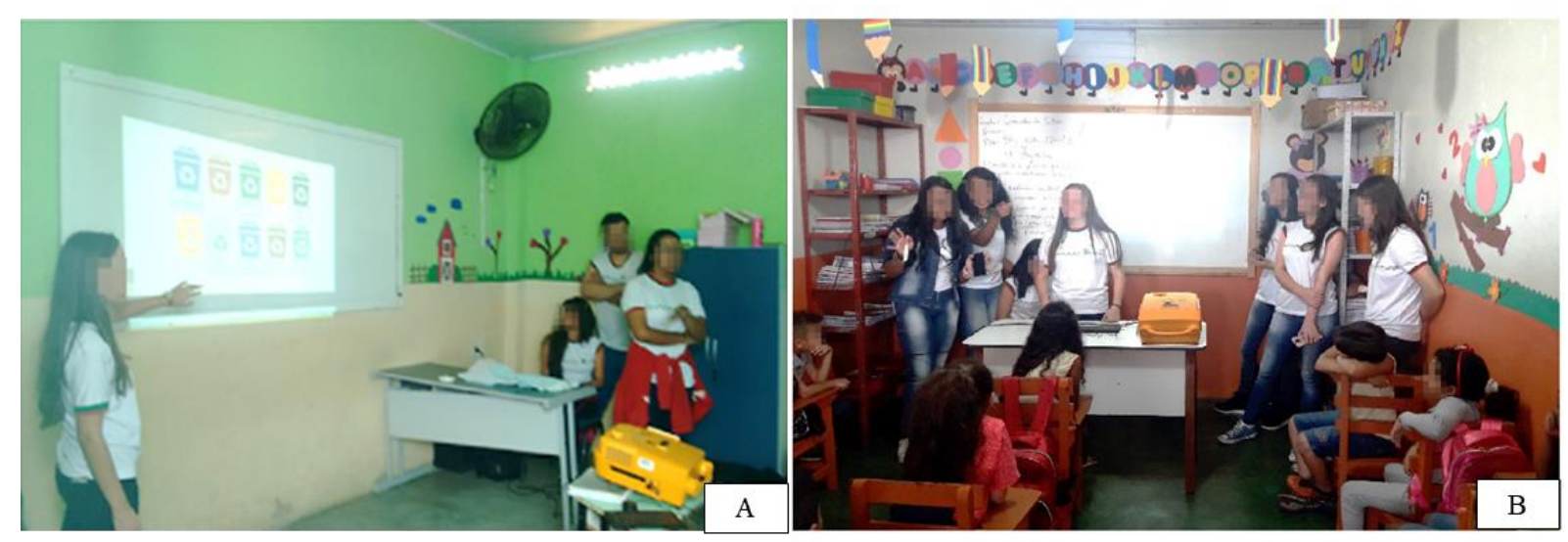

Figura 1 - Palestras ministradas pelos discentes do IFBA durante a intervenção das oficinas de EA. Fonte: dados da pesquisa.

O planejamento de intervenção de práticas de EA foi estruturado a partir da orientação do plano de ação cedido para os discentes aplicadores no intuito de projetar e estruturar as ações de EA. Observaram-se através do uso desse recurso como um elemento norteador para as previsibilidades, demandas e recursos pertinentes ao planejamento. 0 planejamento de ensino é visto como um conjunto de ações para a sistematização do trabalho didático, elemento que conduz de forma ordenada o processo de ensino-aprendizagem. Luckesi (1992) acrescenta o "ato de planejar" sendo caracterizado por ações conjuntas e coordenado na finalidade de alcançar os resultados previstos com passos mais assertivos e de forma econômica. Planejar é uma premissa essencial na prática educacional, pois evita a improvisação de práticas e a falta de dinamismo, além de aperfeiçoar uma maior diversificação de ideias. 0 ato de planejar promove uma leitura clara da prática a ser aplicada, desvia o mediador do agir "às cegas", além de fornecer segurança e se necessário uma reavaliação e reformulação de estratégias. A obtenção de resultados positivos em 
SANTOS, C. L. A.; CAVALCANTE, K. L. (2019)

Ludicidade e aprendizagem significativa na formação de estudantes em educação ambiental: relato de experiência

qualquer âmbito: seja no ambiente educacional, na gestão de metas ou em outras esferas tem como ponto de partida o cuidado do planejar.

Práticas lúdicas diversas intermediadas por jogos didáticos e ações de recreação contextualizadas foram significativas durante o processo de intervenção nas escolas, entretendo tanto os aplicadores como o público alvo (Figura 2-4). O trabalho de Baía; Nakayama (1992) intitulado "A educação ambiental por meio da ludicidade: uma experiência em escolas do entorno do Parque Estadual do Utinga" corrobora com nossas interpretações. 0 autor desse trabalho adota a aplicação de dinâmicas, teatro de fantoches, pinturas em desenhos que re-significam o aprendizado sobre a temática ambiental, tornando o conhecimento prazeroso ao praticar. Santos (2008) destaca que o ensino mecanizado da educação institucionalizada evidencia, por vezes, uma apropriação engessada do método tradicional e não deixa brechas para a aprendizagem com o lúdico, "o aprender se divertindo".

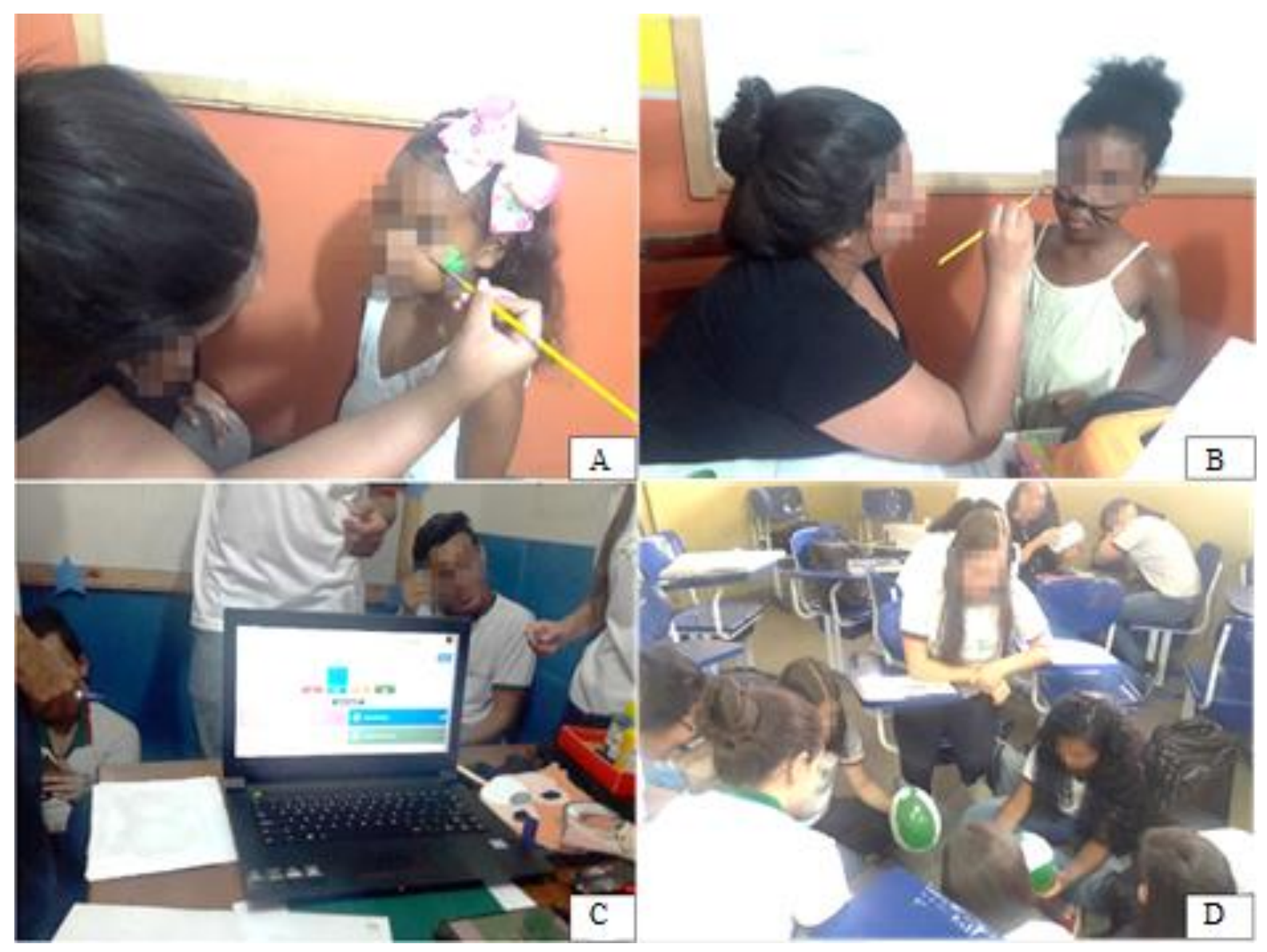

Figura 2 - (A, B) Pinturas faciais com a fauna regional; (C) Jogos interativos personalizados pelos discentes; (D) Confecção prévia de arte em papel machê com jornal e papel de rascunho para produção de máscaras.

Fonte: dados da pesquisa. 


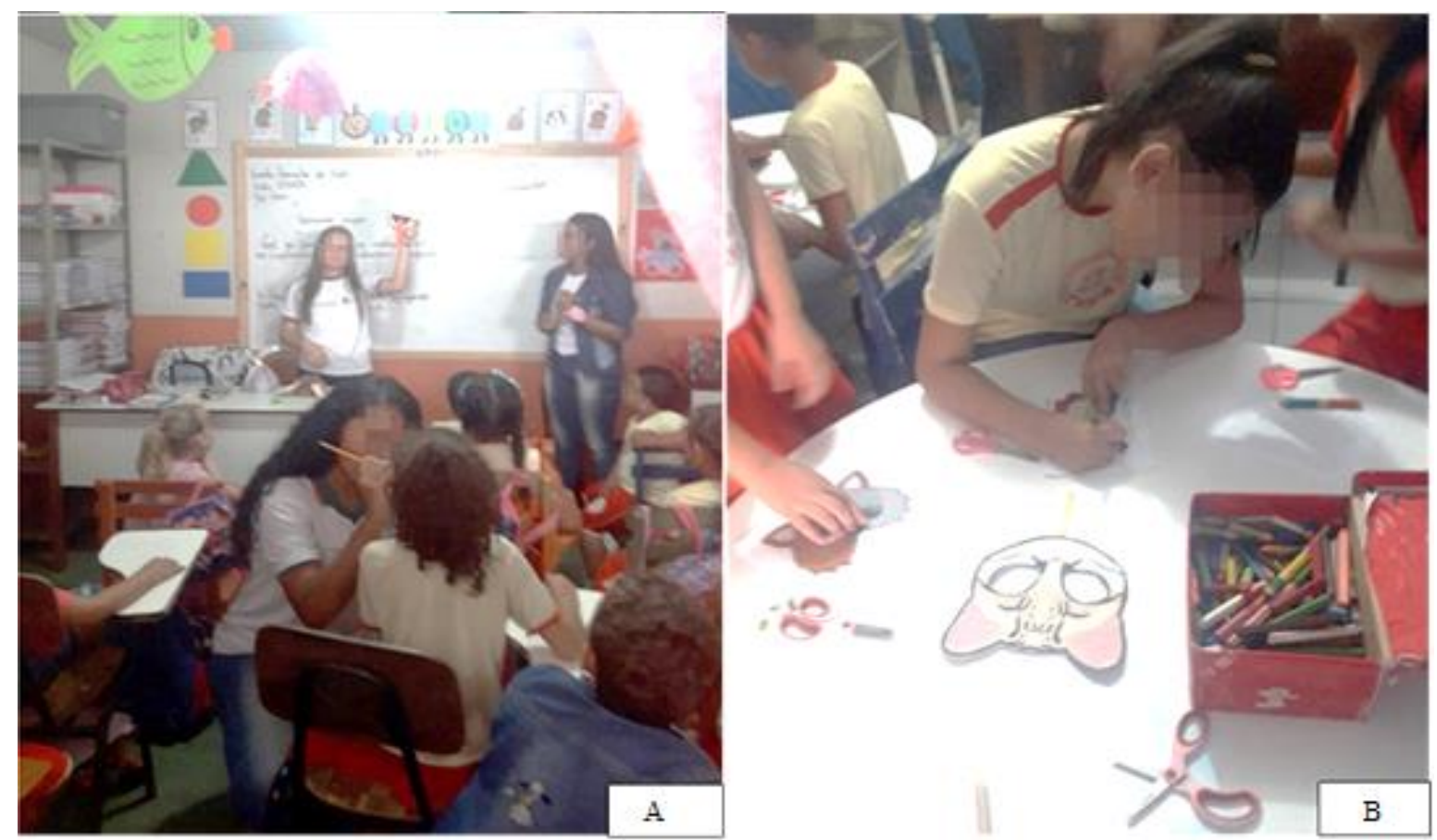

Figura 3 - (A, B) Amostragem do uso das máscaras de diver sos representantes da fauna. Fonte: dados da pesquisa.

Por que a quantidade de resíduos sólidos que produzimos seria algo preocupante? É imprescindível nos atentar sobre a finitude dos recursos naturais e alertar sobre essa problemática em questão. Nesse sentido, Rocha (2016) ressalta que conteúdos procedimentais compreendem o desenvolvimento de técnicas, observações, elaboração e execução de atividades práticas, além de tomadas de decisões no contexto ambiental em que discente vive, podendo interferir na conservação e preservação. A reutilização de material reciclável para a confecção de exemplares lúdicos (Figura 5-A,B), simulação de ecossistema (Figura 5-C) e a orientação efetiva da destinação de resíduos sólidos na coleta seletiva (Figura 6) instiga nas crianças a apropriação de uma cultura do "reaproveitar aquilo que seria descartado", além de proporcionar uma valoração dos recursos naturais. De acordo com Miller (2007) o descarte inadequado de materiais sólidos desencadeia uma série de danos ambientais, seja ela através da polição dos rios, poluição do ar e degradação do solo. Para Calderoni (1998), com efeito, o ato de reciclar ou reaproveitar determinados subprodutos é uma alternativa eficaz para se mitigar esses preocupantes ambientais. Relatos de experiência recentes e de extrema significância sobre vivências no âmbito educacional sócio-ambiental têm sido produzidos no espaço informal, acadêmico e escolar como os conduzidos por Hennrich JR. et al. (2016), Souza et al. (2016), Severo; Cunha (2017), Demoly; Santos (2018) e Rhoden et al. (2018). 
SANTOS, C. L. A.; CAVALCANTE, K. L. (2019)

Ludicidade e aprendizagem significativa na formação de estudantes em educação ambiental: relato de experiência

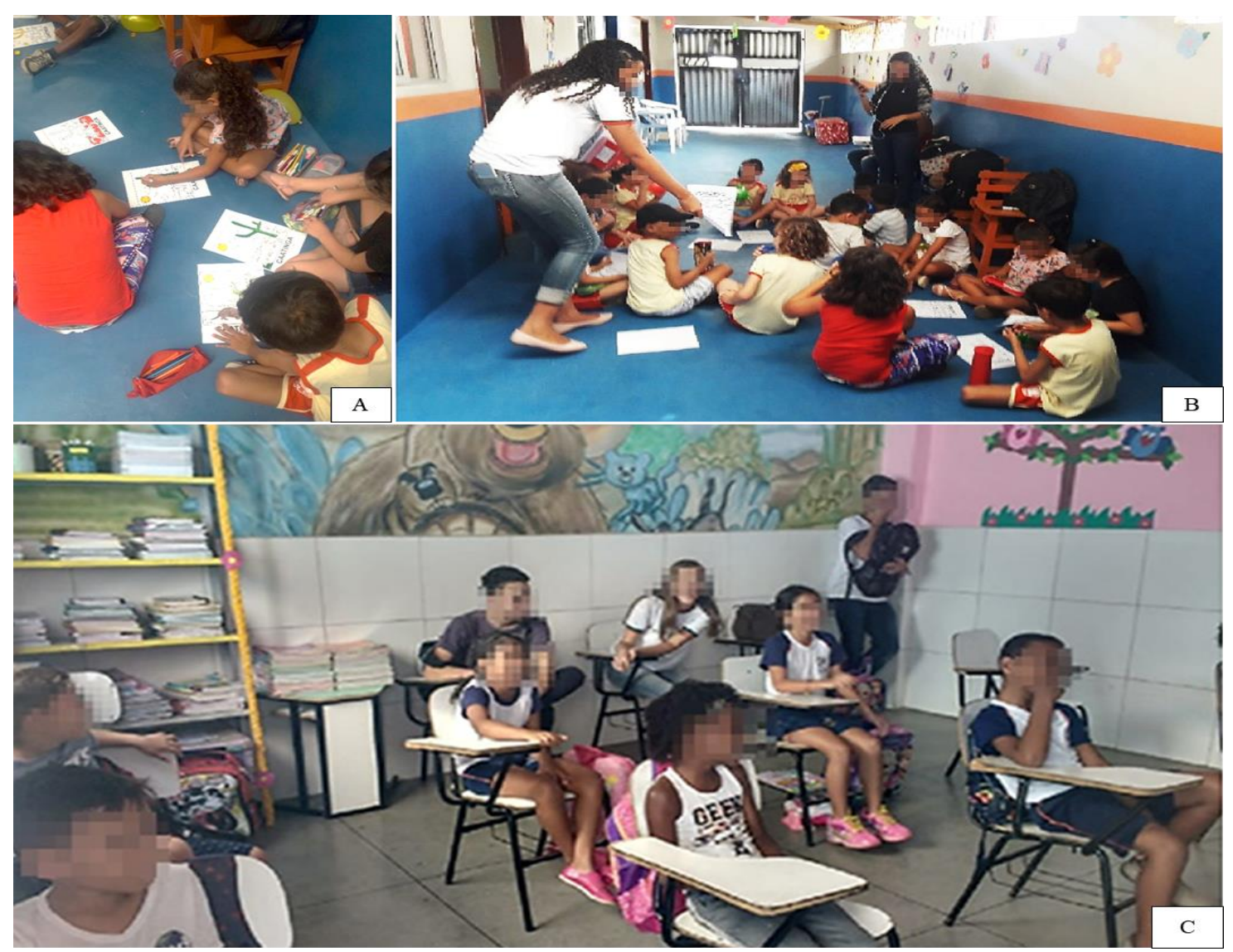

Figura 4 - (A) Pinturas sobre ilustrações do bioma Caatinga; (B) Interação dos estudantes aplicadores com o público alvo; (C) Momento de recreação e interação do público alvo durante a apresentação de práticas lúdicas.

Fonte: dados da pesquisa. 

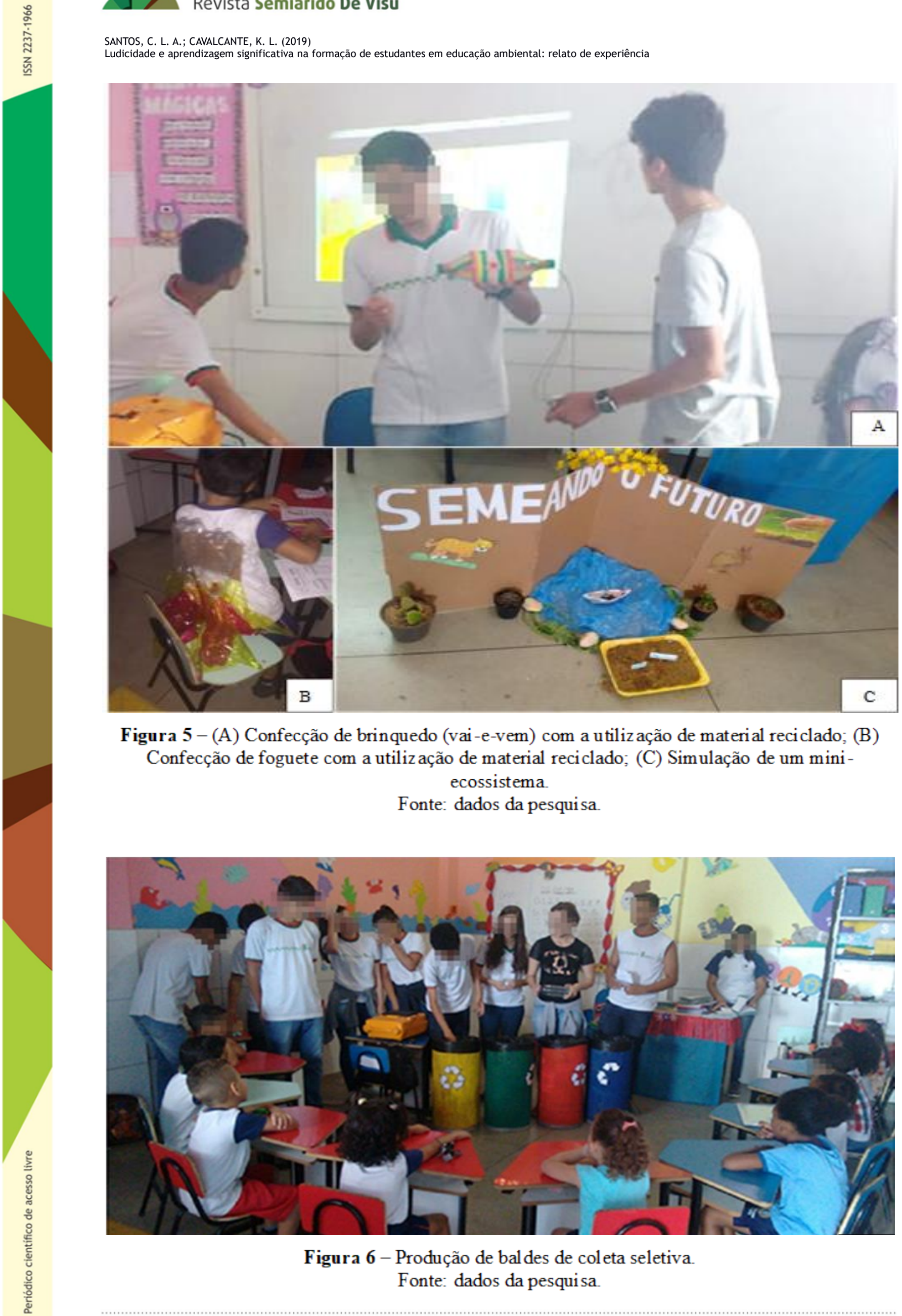

Figura 5 - (A) Confecção de brinquedo (vai-e-vem) com a utiliz ação de material reciclado; (B) Confecção de foguete com a utiliz ação de material reciclado; (C) Simulação de um miniecossistema.

Fonte: dados da pesquisa.

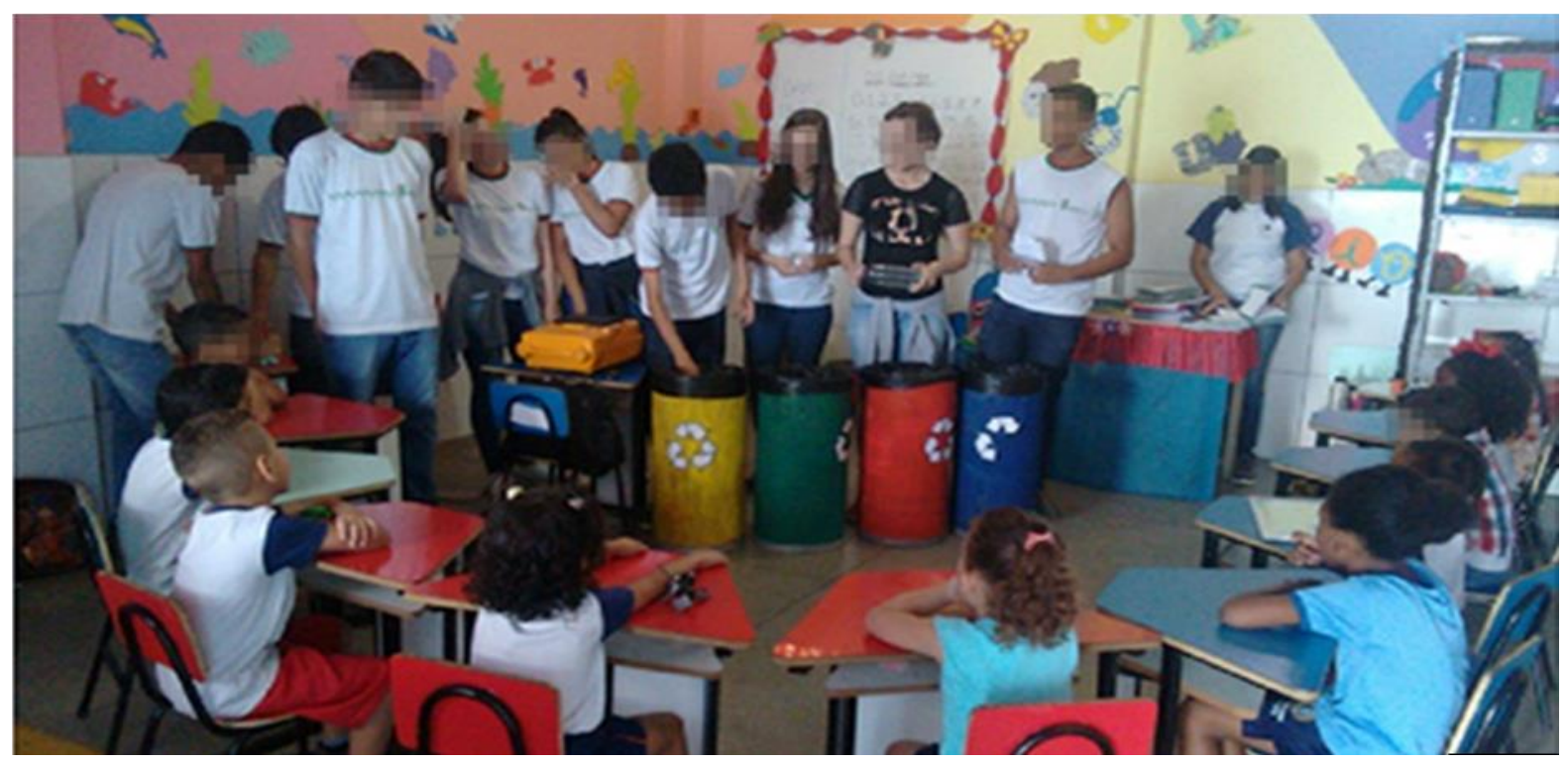

Figura 6 - Produção de bal des de coleta seletiva Fonte: dados da pesquisa 
SANTOS, C. L. A.; CAVALCANTE, K. L. (2019)

Ludicidade e aprendizagem significativa na formação de estudantes em educação ambiental: relato de experiência

A utilização das TICs (Tecnologias da informação e comunicação) foi mediada pelos discentes aplicadores através de recursos diversos, bem como a adoção de projetor multimídia, caixa de som e notebook na finalidade de expor vídeos contextualizados, slides das palestras, jogos interativos e virtuais. A implementação das TICs no planejamento estratégico das práticas de EA fornece uma nova perspectiva para apropriação de didática pelo discente e essa nova demanda denota uma maior intercomunicação do público alvo com o mundo por intermédio dos recursos digitais e informacionais. Fusari (1995, p. 68) destaca serem necessários: “aprender a elaborar e a intervir no processo comunicacional com as mídias, para ajudar na realização da cidadania contemporânea". Ainda, esse mesmo autor enfatiza a efetiva construção da produção social e cultural da comunicação emancipatória mediante a promoção dessas mídias como estratégia metodológica para a socialização de saberes.

Para Martinsi (2008), acompanhar os avanços tecnológicos da contemporaneidade atrelados à práxis educacional exigem novos moldes de intervenção e a adequação desses recursos propicia dinamicidade na estruturação de determinados processos mentais e diversificação de ambientes de aprendizagem. Como exemplificação, o uso de recursos áudio visuais estimula uma maior percepção cognitiva na associação do conteúdo articulada a explanação do mediador e uma abordagem mais interessante do que quando comparado a uma exposição oral isolada.

A proposta de aplicação de oficinas que envolvem práticas interativas promove não apenas uma consciência de promoção à conservação da biodiversidade ou utilização sustentável dos recursos naturais no público aplicador, mas também maior interação pessoal entre os colegas, empatia a didática, eficiência diante de um planejamento prévio, busca de estratégias alternativas, autoconhecimento e desenvolvimento de novas competências e habilidades. Como observado, discentes que demonstraram ter uma personalidade mais introvertida nas costumeiras apresentações de seminário em sala de aula evidenciaram a descoberta de novas habilidades diante das práticas propostas. Pontua-se ainda, a adequação da linguagem como processo adaptativo pertinente durante a intervenção das palestras e práticas. A principio os discentes se mostraram enquadrados aos moldes de apresentação de seminário que são habituados durante as apresentações de trabalho avaliativo de sala de aula, porém ao perceber o feedback do público alvo imediatamente procederam a uma postura mais coerente a faixa etária ao ministrar as atividades.

No presente estudo, uma equipe dos discentes aplicadores excedeu a aplicação das oficinas in situ e publicaram as produções da encenação musical (Figura 7-A, B) no canal do youtube. Esse evento é apontado como um dado relevante, pois esses discentes reproduzem o saber assimilado promovendo uma maior efetividade no programa de educação ambiental por intermédio de sua própria autonomia. Para Silva et al. (2014), diante de uma sensibilização de grande apelo ambiental o indivíduo jovem transforma-se em um agente multiplicador do aprendizado, propagando aos familiares e vizinhos conceitos e informações de como lhe dar com as urgências ambientais. 


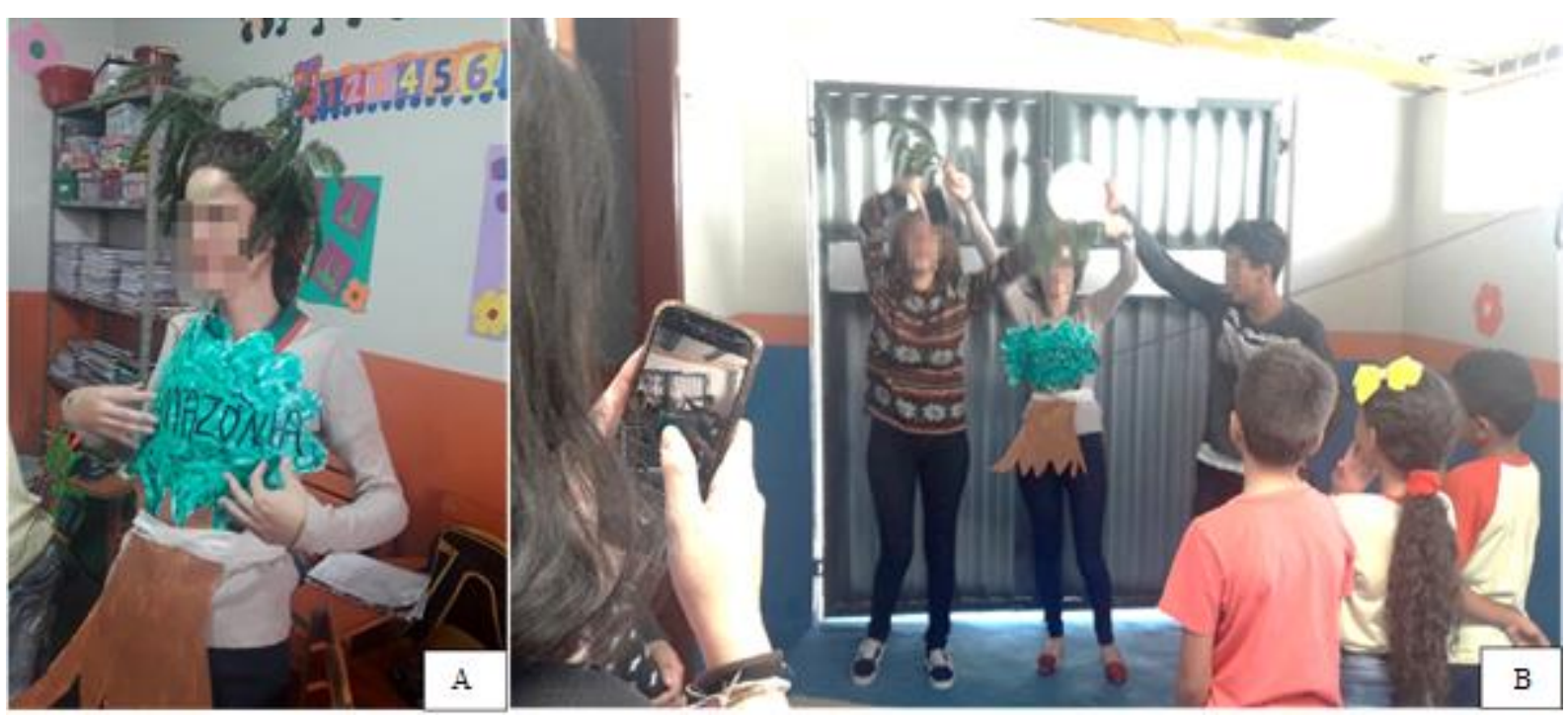

Figura 7 - (A) Caracteriz ação para encenação musical; (B) Encenação musical da paródia "SOS Amazônia" da música "Era uma vez" de Sandy e Júnior.

Fonte: dados da pesquisa.

\section{Conclusões}

As atividades lúdicas mediadas pelos discentes aplicadores foram instrumentos que extraíram não somente o "brincar" e o "aprender" no público alvo, mas esse reflexo foi estendido aos mediadores, ou seja, aos discentes aplicadores da EA. A reutilização de material reciclável para a confecção de exemplares lúdicos, a orientação efetiva da destinação de resíduos sólidos na coleta seletiva e suas implicações sócio-econômicos foram fatores importantes para se instaurar uma reflexiva postura de valoração dos recursos naturais e contextualização da realidade, construindo uma aprendizagem de fato significativa. Contudo, a aprendizagem significativa foi subsidiada pela inserção da experiência e a vivência do estudante no currículo escolar, evidenciados tanto durante no processo de preparação das práticas quanto nos momentos de intervenção fora do espaço educacional. Frente a experiência relada, as práticas de EA moldaram uma formação de educandos comprometidos com a preservação ambiental e apropriação de uma postura de agentes transformadores da realidade.

\section{Referências}

BAÍA, M. da C. F.; NAKAYAMA, L. A Educação Ambiental por meio da ludicidade: uma experiência em escolas do entorno do Parque Estadual do Utinga. Margens, Abaetetuba, p. 89-112, 2013.

BOGDAN, R. C.; BIKLEN, S. K. Investigação qualitativa em educação. Portugal, Porto, 1994. 335 p. 
SANTOS, C. L. A.; CAVALCANTE, K. L. (2019)

Ludicidade e aprendizagem significativa na formação de estudantes em educação ambiental: relato de experiência

CABRERA, W. B. A ludicidade para o ensino médio na disciplina de biologia: contribuições ao processo de aprendizagem em conformidade com os pressupostos teóricos da aprendizagem significativa. Dissertação (Mestrado). Universidade Estadual de Londrina, Londrina, 2007. 158 p.

CABRERA, W. B.; \& SALVI, R. F. A ludicidade no Ensino Médio: Aspirações de Pesquisa numa perspectiva construtivista. In: ATAS DO V ENCONTRO NACIONAL DE PESQUISA EM EDUCAÇÃO EM CIÊNCIAS, 5, Bauru, 2005. Anais... Bauru, SP, ASSOCIAÇÃO BRASILEIRA DE PESQUISA EM EDUCAÇÃO EM CIÊNCIAS, 2005. p. 1 - 11.

CALDERONI, S. Os bilhões perdidos no lixo.

2. ed. São Paulo, Humanitas, 1998. 343 p.

CAMELO, A. N. B. Educação ambiental no ensino fundamental: um estudo de caso da Escola Estadual de Ensino Fundamental. Monografia (Graduação). Universidade Estadual da Paraíba, Paraiba, 2011. 66 p.

CAMPOS, D. B.; CAVALARI, R. M. F. O professor de Biologia enquanto "sujeito ecológico": conhecimentos, valores e participação política na prática docente. Revista Eletrônica de Educação, v. 12, n. 1, p. 184-198, jan./abr. 2018.

CARRIL, M. da G. P.; NATÁRIO, E. G.; ZOCCAL, S. I. Considerações sobre aprendizagem significativa, a partir da visão de Freire e Ausubel - uma reflexão teórica. Revista Multidisciplinar de ensino. v. 6, p. 68-78, 2017.

CARVALHO, I. C. de M. O sujeito ecológico: a formação de novas identidades na escola. In: PERNAMBUCO, Marta; PAIVA, Irene. (Orgs.). Práticas coletivas na escola. Campinas: Mercado de Letras, 2013.

CHALITA, G. Educação: a solução está no afeto. São Paulo, Gente, 2004. 151 p.

DEMOLY, K. R. do A.; SANTOS, J. S. B. dos. Aprendizagem, educação ambiental e escola: modos de en-agir na experiência de estudantes e professores. Ambiente \& Sociedade. v. 21, p. 1-20, 2018.

DIAS, G. F. Educação Ambiental: princípios e práticas. 9 ed. São Paulo, Gaia, 2004. 541 p.

DINIZ, B. Relato de experiência: a educação ambiental na formação de professores. Revista SimbioLogias, v. 1, p. 1-12, 2008.

FUSARI, M. F. R. TV, recepção e comunicação na formação inicial de professores em cursos de Pedagogia. Revista do Centro de Educação, v. 24, p. 67-91, 1995. 
SANTOS, C. L. A.; CAVALCANTE, K. L. (2019)

Ludicidade e aprendizagem significativa na formação de estudantes em educação ambiental: relato de experiência

HENNRICH JR, E. J.; CARNIATTO, I.; NOGUEIRA, J. R. KOPPE, M. Escola Rural Sustentável: um relato de experiência em uma escola do município de Marechal Cândido Rondon- Paraná- Brasil. Revista Eletrônica do Mestrado em Educação Ambiental. v. 33, p. 132-151, 2016.

LUCKESI, C. C. Planejamento e avaliação escolar: articulação e necessária determinação ideológica. IN: BORGES, S. A. O diretor articulador do projeto da escola. São Paulo, FDE, 1992.

MARTINSI. M. C. Situando o uso da mídia em contextos educacionais. 2008. Disponível em: <http://www.educadores.diaadia.pr.gov.br/arquivos/File/cursoobjetosaprendizagem/situando_uso midias_mec.pdf>. Acesso: 22 jan. 2019.

MINISTÉRIO DA EDUCAÇÃO E CULTURA-MEC. Parâmetros Curriculares Nacionais: meio ambiente e saúde. Brasília, 1997. 128 p. Disponível em: <http://portal.mec.gov.br/seb/arquivos/pdf/livro0 91.pdf>. Acesso em: 04 fev. 2019.

MILLER, G. T. Ciência ambiental. 11 ed. São Paulo, Thomson, 2007. 123 p.

MOREIRA, M. A. Aprendizagem significativa. Brasília, UnB, 1999. 129p.

NARDY, M.; LABURÚ, C. E. Aprendizagem significativa e educação ambiental: um possível diálogo a partir de estratégias multimodais. Revista em aprendizagem significativa, v. 4, p. 26-36, 2014.

OLIVEIRA, A. F. T. PCN's e Meio Ambiente: um tema transversal. Monografia (Graduação). Universidade Estadual da Paraíba de Guarabira, Paraíba. 2002.

PELIZZARI, A. KRIEGL, M. DE L.; BARON, M. P.; FINCK, N. T. L.; DOROCINSKI, S. I.. Teoria da aprendizagem significativa segundo Ausubel. Revista PEC, v. 2, p. 37-42, 2002.

RANGEL T. R.; MIRANDA A. C. Atividade lúdica como inserção da educação ambiental no ensino fundamental. Revista Educação Ambiental em Ação. n. 5, 2016.

RHODEN, V.; RIBEIRO, L. B.; SALOMONI, S. E. Relatos de atividades de conscientização e educação ambiental sobre o destino correto dos resíduos sólidos em São Borja - RS. Revista Eletrônica de Extensão, v. 15, p. 77-86, 2018.

ROCHA, L. B. A importância das práticas e ciências para o processo ensino aprendizagem. Revista Científica Intelletto, v. 1, n. 3, p. 28-46, 2016.

RODRIGUES, M. G. S. \& COSTA, R. de S. O. da. A integração da educação formal e não- formal: participação e cidadania. In: CONGRESSO ACADÊMICO SOBRE MEIO AMBIENTE E DESENVOLVIMENTO, Rio de Janeiro, 2004. Anais... Rio de Janeiro, RJ, Ebape-FGV, 2004. 
SANTOS, C. L. A.; CAVALCANTE, K. L. (2019)

Ludicidade e aprendizagem significativa na formação de estudantes em educação ambiental: relato de experiência

SANTOS, S. M. P. A ludicidade como ciência.

2. ed. Petrópolis, Vozes, 2008. 227 p.

SEVERO, A. F.; CUNHA; B. P. da. Relato de experiência de educação ambiental na Semana da Ciência, Tecnologia e Cultura da Universidade Federal do Rio Grande do Norte. Revista da Faculdade de Direito da UFRGS, n. 36, p. 265-277, 2017.

SILVA, H. R. T.; EGERT, P.; TEIXEIRA, C. M. Educação ambiental: uma prática de alunos universitários nas escolas de ensino fundamental. Revista Gestão \& Sustentabilidade Ambiental, v. 3, p. 250-256, 2014.

SOUZA, I. R. de; Almeida, R. A. de. Relato de experiência: trajetória de construção da educação no/do campo na escola municipal rural São Joaquim polo e extensões em Selvíria-MS. Revista Eletrônica da Associação dos Geógrafos Brasileiros, n. 24, p. 79- 110, 2016.

THIOLLENT, M. Metodologia da pesquisa- ação. 14. ed. São Paulo, Cortez, 2005. 108 p.

TELLES, M. DE Q.; DA ROCHA, M. B.; PEDROSO, M. L.; MACHADO, S. M. DE C. Vivências integradas com o meio ambiente. São Paulo: Sá, 2002. 144 p.

TESSARO, J. P. Discutindo a importância dos jogos e atividades em sala de aula. Disponível em: <http://www.psicologia.com.pt/artigos/textos/A0356.pdf>. Acesso em: 10 jan. 2019. 